\title{
Research on the Design of Red Culture Tourism Sign Guiding System-Taking the Former Central Soviet District of Gannan as an Example
}

\author{
Jia Wang ${ }^{1, *}$, Min $\mathrm{Li}^{1}$, Xiaoqing Ma ${ }^{1}$, Jicong Wang ${ }^{1}$ \\ ${ }^{1}$ Art College, Jiangxi University of Finance and Economics, Nanchang City, Jiangxi, Province, 30013, China
}

\begin{abstract}
The red culture is the most characteristic and representative cultural resource in the Central Soviet Area of Gannan. Facing the rich central resources of the Central Soviet Area, it is of great significance to promote the "red culture" tourism. The sign-oriented system plays the role of guidance, instruction and explanation in the tourism process. It is an important part of the environmental layout, atmosphere creation and cultural upgrading of the entire red cultural scenic spot. This paper takes the red culture of the Central Soviet Area in Gannan as the background, and takes the cradle of the Republic of Ruijin City in the Central Soviet Area as an example. Based on the design orientation of the red cultural tourism area, this paper analyzes the current situation and existing problems of the guiding design of the central Soviet area of Gannan. Under the CIS theory, a mesh configuration grading system is built to create a red cultural tourism area sign-oriented system.
\end{abstract}

\section{Exploring the background of the red culture in the Central Soviet Area of Gannan}

The central revolutionary base area, also known as the Central Soviet area. It refers to the revolutionary base area established by the Communist Party of China in southern Jiangxi and Western Fujian during the Land Revolutionary War from 1929 to 1934[1]. The former Central Soviet Area of Gannan includes three prefecture-level cities in Ganzhou, Ji'an, and Fuzhou of Jiangxi Province, and has 13 counties including Ruijin[2]. Ruijin is the center of the Central Revolutionary Base, the birthplace of China's first red government, the Provisional Central Government of the Chinese Soviet Republic[3], and the starting point of the Red Army's Long March 25,000 miles, known as the "red old capital" and "cradle of the Republic". The Red Capital Ruijin has rich red cultural tourism resources and is a national 5A-level scenic spot. To date, there are 115 revolutionary sites and memorial buildings, including Ye Ping's Xie Family Ancestral Hall (Site of the First National Congress of the Chinese Soviet), the Great Hall of Sha Zhouba (Auditorium of the Provisional Central Government of the Chinese Soviet Republic), the Red Well(with the largest number of drinkers in the world), Yun Shishan (the first mountain of the Long March), the sites of 52 former central state ministries, 35 key national cultural relics protection units and more than 10,000 precious cultural relics[4]. These numerous revolutionary relics together constitute the sacred land of Ruijin, its rich red cultural heritage also makes it one of the first national patriotic education demonstration bases announced by the central propaganda department and one of the national red cultural tourism classic scenic spots.

\section{Concept and content definition of red cultural tourism sign guiding system}

\subsection{Concepts of signage and wayfinding systems}

Signage and Wayfinding Systems refers to the overall solution of space and information environment, which is guided by systematic design, comprehensively solves the functions of information transmission, identification and image transmission to help strangers to get the information they need in the fastest time[5].

\subsection{Content definition of red cultural tourism scenic spot guidance system}

The red regional cultural spiritual power contained in the Central Soviet Area of Gannan is infinite. There is a comparison of the sign oriented design in its red cultural tourist area Clearly defined, it refers to the internal identification of a specific scenic area (red cultural tourism scenic area), which has a certain speciality and focus compared with the general scenic area identification. And its sign should have national personality and local characteristics, and form a system with the red culture reflected in the entire scenic area.

"Corresponding author e-mail: sunny_wjia@163.com 
Therefore, the artistic aesthetic requirements are relatively high, and its sign-oriented figurative manifestation should represent the red culture, and it can make the tourist visiting learners form a heart-inspired inspiration for the red cultural spirit in the process of wayfinding which is unmatched by the general scenic spot-oriented signs.

\section{Analysis of current situation and problems of scenic spots}

Through field investigations of the Cradle Scenic Spot of the Red Capital Ruijin Republic, the author found that its sign-oriented design has certain planning, but there are still many unsatisfactory aspects, which are specifically reflected in:

\subsection{Does not reflect the needs in behavioral activities.}

As a first time visitor to the History Museum of the Central Revolutionary Base, I walked from the square to the museum and didn't see any signage guiding me, instead, on the way back from the Chinese Soviet Memorial, a guide sign for the History Museum of the Central Revolutionary Base is hidden in the bushes (Fig.1). The signboard of the History Museum of the Central Revolutionary Base is only seen on the right side of the small downhill to the right of the museum. Strictly speaking, its location setting is not reasonable and does not conform to the walking habits of pedestrians.

\section{2 lack of regional sign guidance map.}

When I entered the History Museum of the Central Revolutionary Base, I wanted to have a detailed understanding of the museum's exhibition halls and the number of layers in the museum, but I found that there was no overview map of museum information. Then, I found an electronic information screen on the left side of the museum. So, I wanted to understand the general situation of the scenic spot through the dynamic display of the electronic information screen, but unfortunately I met the state of the unconnected network (Fig. 2-3), but helplessly only know that the museum has three floors by asking the field staff. And then, I found that starting from the second floor the number of people visiting each floor is getting less and less. By the third floor, there are almost no people. The visitor assumes that he has not asked the staff without seeing the overview map of the scenic spot. He may leave after visiting the first floor directly. Thus judging that the guiding signs in the museum lack scientific, holistic and systematic. When I went deep into the Red Well and Yeping scenic spots, I found that there were the distribution map of cradle scenic spots of the Republic and the panoramic map of tour guides in each scenic spot outside the tourist center, but when I really went deep into the scenic spot through the tourist center, I found that there was no overview map at this location when I needed the panoramic map of tour guides in the scenic spot most, which was unreasonable (Fig. 4).

\subsection{Unclear guidance information of intersections.}

There is a fork in the crowd route square of Red Well Scenic Area. One side is the entrance direction and the other is the exit direction. The sign-oriented setting here is not obvious. Some tourists visit the attractions directly from the exit. Therefore, clear guidance signs should be set at intersections, because it plays a vital role in determining the direction of the road during the path finding process.

\subsection{Insufficient accuracy and lack of continuity in the setting of guide signs in scenic spots.}

When I entered the "Site of the second National Congress of the Chinese Soviet", I found that there are deviations between the direction of the arrow indicating the direction and the actual location of the building, and the continuity of the guide signs is insufficient. The author came down from Hongge Mountain and wanted to visit the "Auditorium of the Provisional Central Government of the Chinese Soviet Republic", and according to the direction of the guide arrow, but still could not find the destination. Therefore, the judgment of the setting of the guide sign in this area was not available. And after asking the staff, we know that we would walk along the path paved with green bricks to see the auditorium because when it was built, in order to prevent discovered by enemy aircraft, the octagonal auditorium was hidden among lush tall trees, from the Fig.5 it can be seen that the path is curved and hidden, but no guidance sign is set. From the perspective of visitors, in this above condition, the continuity of the guidance information in its space should be ensured according to the current surrounding environment. Pay special attention to the key nodes information settings, so as not to cause tourists' psychological insecurity.

\subsection{Inconsistent color performance of guide sign information.}

In the design of the sign-oriented system, the information presentation method should be consistent, and the color processing in the sign information interface should be coherent, and the color harmony and unity in the region should be paid attention to while fully considering its visual effect. The author saw outside the Red Well Scenic Area Tourist Center that the arrow color of the scenic entrance marked in the tourist panorama is red, and the exit arrow color is orange. However, in the local guide map deep into the scenic area, the arrow color of the exit is white (Fig. 6). In addition, both belong to the cradle of the Republic, but the identification symbols between the scenic area and the scenic area are different in color. For example, the color of the arrow legend at the entrance and exit of the Red Well Scenic Area overview map and the Site of the Second National 
Congress of the Chinese Soviet Scenic Area overview map are not the same (Fig. 7); Furthermore, the author found that the legend of your current location is consistent with the corresponding legend in the form of the overall distribution map of the Republic Cradle Scenic Area, but the color is not consistent (Fig. 8). Therefore, it is necessary to pay attention to the problem that the excessive color information differentiation causes logical confusion in the design.
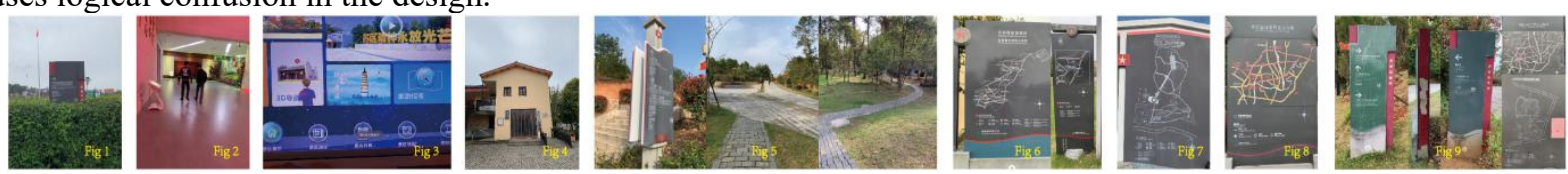

Fig. 1 Guide board covered by Greenery.

Fig. 2-3 Electronic information screen at the left of the entrance of the museum.

Fig. 4 Entrance of Red Well scenic spot.

Fig. 5 Inside the Chinese Soviet Memorial Park.

Fig. 6 The color of the arrows at the entrances and exits of different signs in Red Well Scenic Area is inconsistent.

Fig. 7 the Site of the second National Congress of the Chinese Soviet Scenic Area overview map.

Fig. 8 Map of Republic Cradle.

Fig. 9 Directional signs damaged by nature and man-made.

\section{Countermeasures and suggestions}

Based on the above-mentioned field observations and analysis on the current status of the guide sign system in the red cultural tourist area, this paper puts forward the concrete solution strategies and methods on how to construct a guiding and operability red culture tourism guide sign system.

\subsection{Build a mesh configuration classification system}

On the basis of grasping the geographical environment, road setting and distribution of red cultural tourist areas, we should fully tap the red resources and plan classic routes. Based on the principle of the construction of spatial points, lines, and areas, the entire scenic area plan is a whole area, and the roads for visiting and playing are a line, while the sign guide is a distribution point on the line, and a mesh classification is constructed from the whole to the part in turn. Level 1: The clear guiding signs (including direction and distance) shall be set up on the main road of traffic on the edge of the scenic spot, which also has a good role in promoting the red culture brand. Level 2: It is set on the main road in the scenic area and at the main entrances and exits (especially pay attention to the panoramic guide map of the large scenic area at the entrance and exit of the main road and the area within 300 meters walking distance). Level 3: Set at the intersections of roads in each zone (pay special attention to intersections) to indicate the orientation information of the main old buildings in the scenic area. Level 4: Clearly set the guide signs for the buildings and front buildings of each revolutionary old site and the direction signs between the building and the building. Level 5: Deep into the specific space identification in each building in the scenic spot.

\subsection{Based on the CIS theory to create a red cultural tourism area sign guidance system}

Corporate Identity System hereinafter referred to as CIS, is composed of Mind Identity, Behavior Identity and Visual Identity[6]. Japanese urban CIS expert Professor Sato $\mathrm{Yu}$ believes that through urban CIS design, the effect that should be achieved is that urban residents are proud, visitors are envious, and foreign investors are satisfied[7]. Therefore, we can reflect the development concept of the red cultural tourism area and the red revolutionary spiritual culture in the behavior identity and visual identity to form an integrated recognition system, so that tourists can feel the red revolutionary history "alive" in a specific red cultural environment. The introduction of CIS into the sign-oriented system is to graft the red cultural image strategy onto the image strategy of the scenic spot identification in the identification-oriented mesh configuration classification system. The famous American urban planning and design master Kevin Lynch's book "The image of the City", people describe the five major elements of urban space: roads, borders, regions, nodes, and landmarks[8]. These five elements can also be regarded as the five elements of red cultural scenic spot. No matter from the regional name sign of red scenic spot, path boundary sign, important node sign of scenic spot, or characteristic building sign of scenic spot, from the form to the spatial layout, there should be an overall and unified red connotation feature and visual coherence. Through the CIS system theory, the red scenic spot signs combine the regional red spiritual connotation, historical humanistic features, natural geographic features, etc. And to create a set of red cultural scenic spot orientation and recognition system which is coordinated with the red spirit connotation, adapted to the scenic spot environment and with high recognition. 


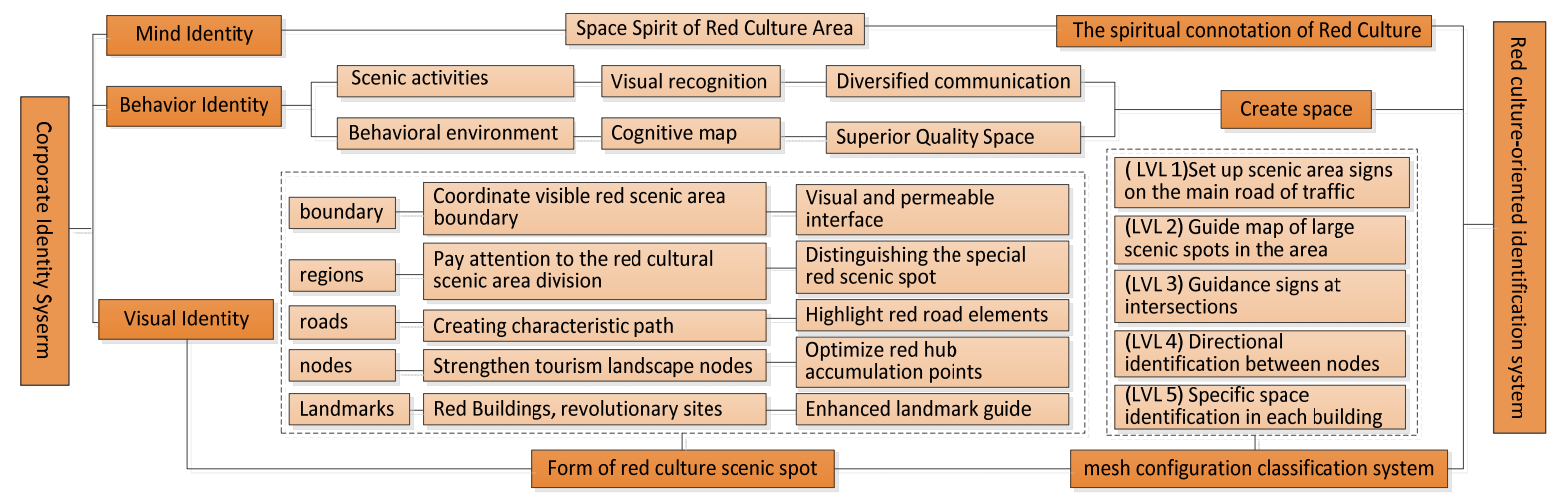

Fig. 10 Schematic diagram of red culture-oriented identification system strategy based on CIS theory

\subsection{Strengthen maintenance management}

The design of the sign-oriented system is an indispensable part of the planning of facilities in the red cultural scenic area. In order to ensure the sign-oriented system can meet the long-term use requirements, the relevant government departments should conduct overall maintenance and management. For signs replacement and movement, human factors such as graffiti and small advertisements should be cleaned and repaired in a timely manner. In order to adapt to the development of the times, designers are also required to carry out creative updates and expand the sign-oriented system. In this regard, it is also recommended that the relevant departments formulate quarterly and annual management and maintenance forms, and responsibilities to others to form an effective management mechanism.

\section{Outlook}

As an integral part of the red tourism planning, under the background that more service posts are replaced by artificial intelligence, when the wayfinding process gets lost and no service personnel can ask, the serviceability provided by the guide signs becomes more important. Based on the innovative development of science and technology, the design of the guide signs in the red cultural tourism area should also keep pace with the exploration of the combination of digital technologies on the basis of traditional guide signs to increase tourist participation, interaction, experience, and build a new service model for the guide sign system design.

\section{Acknowledgment}

Fund Project: This work was supported in part by the "Twelfth Five-Year Plan" of the Social Science Research of Jiangxi Province of China (Project Approval Number: 14YS16), by the student research project of Jiangxi University of Finance and Economics (Item Number: xskt19425).

Photo source: The photos and tables appearing in the article are all self-photographed and drawn by the author.

\section{References}

1. Lin, W.M. (2011) Overview of red historical sites in the soviet district of Qingliu county. Fujian Wenbo. 3:104-110.

2. Xu, S.J. (2013) Vocational education development in the Central Soviet Area of Gannan: Status Quo and Expectations. Vocational and Technical Education. 24: 69-73.

3. Wang, X.L. (2011) On the effective use of the red army's long march tourism resources in college tourism teaching. Theory Research. 5: 225-226.

4. Wan, W.L. (2013) Speed up the development of the "red capital" tourism industry. Contemporary Jiangxi. 10: 49-50.

5. Liu, W.Z. (2014) Analysis on landscape design and transformation of commercial pedestrian street-taking Guilin Zhengyang pedestrian street as an example. Modern Decoration Theory. 2: 61.

6. Ma, C.L. (2012) On the introduction and implementation of the image strategy of county tourist attractions. Press Circles. 4:23-26.

7. Huang, Z.H. (2009) On the role of urban CIS in building urban brand image. Packaging Engineering. 6:134-136.

8. Kevin Lynch, Xiang B.R.translated. (1990) The image of the city. China Construction Industry Press. 42-84.

9. Li, M., Hu, Y. (2012) Research on design method of city-oriented sign system. New Arts. 5:68-72 